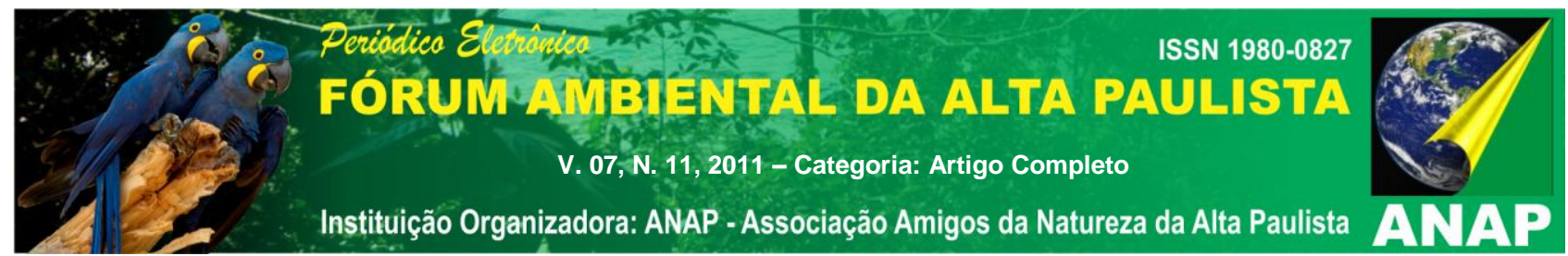

\title{
MARKETING VERDE E SUA CONTRIBUIÇÃO NAS ORGANIZAÇÕES
}

\author{
Edilene Mayumi Murashita Takenaka ${ }^{1}$ \\ Rafael Moreira Campos ${ }^{2}$ \\ Gleice Kelly dos Reis Teixeira ${ }^{3}$
}

\begin{abstract}
Resumo: A pesquisa realizada aborda a conjuntura atual em que emerge, no Brasil, uma sociedade de consumo preocupada com as questões ambientais seja no consumo de bens duráveis, não duráveis e também o consumo de serviços prestados. Assim, o objetivo da presente pesquisa foi demonstrar a necessidade da conscientização acerca da Gestão Ambiental nas empresas como forma de estratégia de marketing apresentando um diferencial dentro do âmbito organizacional para atender a um mercado consumidor preocupado com a qualidade do meio ambiente em que vive ao enfocar uma empresa da área de prestação de serviços de saúde localizada no município de Presidente Prudente/SP. Para uma melhor abordagem do tema, foi utilizada a pesquisa bibliográfica com a leitura de materiais escritos por autores relacionados à área seguida do uso da pesquisa descritiva e da abordagem qualiquantitativa a partir do estudo de caso realizado na empresa citada, com a aplicação de questionários junto a funcionários e usuários de seus serviços. Ao final, com base nas informações obtidas, concluiu-se que a empresa analisada tem um amplo caminho a percorrer, uma vez que as informações coletadas demonstram uma iniciação muito tímida nas questões que abrangem o marketing verde.
\end{abstract}

Palavras-chave: Gestão ambiental, empresa, marketing verde

\section{INTRODUÇÃO}

Os apelos de conservação do meio-ambiente têm se tornado mais constantes e se agravam com o espaço que têm ocupado na mídia quanto às preocupações frente a uma biosfera de fato condenada à calamidade: efeito estufa, aumento do buraco na camada de ozônio, desmatamento, tráfico de animais silvestres, queimadas, entre outros, são as causas da metamorfose do cenário ambiental global.

\footnotetext{
1 Economista e Doutora em Geografia, professora do curso de Administração-Unoeste. edilene@unoeste.br

${ }^{2}$ Graduando em Administração, Unoeste.rafael_sbento@hotmail.com

${ }^{3}$ Graduando em Administração, Unoeste.gkrt_@hotmail.com
} 


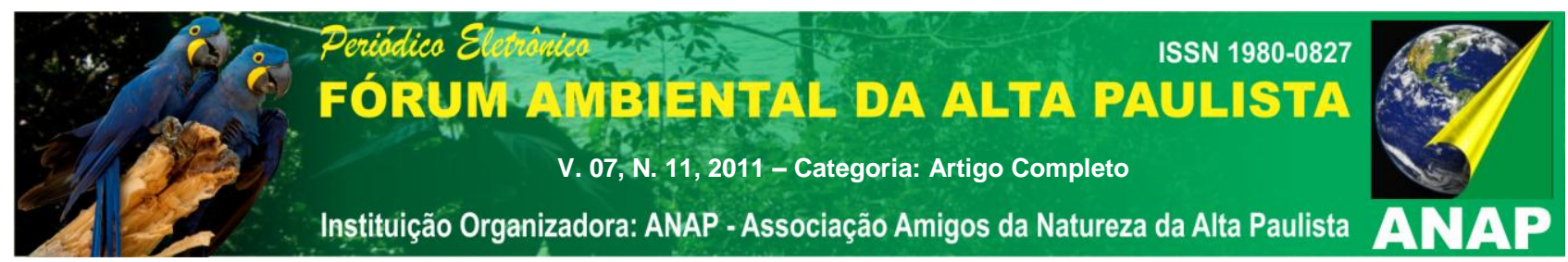

Diante dessa massificação contextual que envolve a preocupação com questões ambientais, inicia-se uma mobilização social acentuada pelo aumento de debates e propostas ambientais para efetivamente se prevenir o pior. Várias conferências mundiais são realizadas, como por exemplo: Estocolmo 1972, Rio-92 e Cúpula Global ou Rio+10.

Nesse sentido o enfoque ambiental adentra, ou pelo menos, deveria entrar na pauta de ações a serem desenvolvidas junto às organizações empresariais que desejam atender a um mercado consumidor preocupado com a qualidade do meio ambiente em que vive atrelando produtividade e sustentabilidade nesse processo.

Como diz Oliveira (2008, p.23): "crescimento econômico e proteção ambiental não são incompatíveis e podem acontecer ao mesmo tempo. Isso é hoje chamado de ecoeficiência ou ecoeficácia.".

Maximiano (1995, p.12) reforça tal afirmação ao acrescentar que: "um dos componentes importantes dessa reviravolta nos modos de pensar e agir foi o crescimento da consciência ecológica, na sociedade, no governo e nas próprias empresas".

Os consumidores atuais, mais conscientes em relação à necessidade de proteger 0 meio ambiente, assumem uma postura diferenciada no momento do consumo que é selecionar aquelas empresas que adotem mecanismos que resultem em um menor dano ambiental.

A produtividade, outrora aliada à lucratividade, atualmente agrega uma conotação mais social: sustentabilidade. Concernente às empresas Oliveira (2008) diz que as mesmas não possuem somente impactos econômicos, mas também sociais, ambientais e políticos, que a sociedade não pode desprezar. Por isso nota-se que as organizações reformularam a maneira de lidar com a sociedade, resultando em adoção de diretrizes sociais, entre elas a ambiental.

Gerir seus recursos produtivos para garantir produtividade atrelada à conservação ambiental bem como a lucratividade e a satisfação do consumidor passa a ser o real desafio para as organizações atuais.

\section{1 - Justificativa e relevância do tema}




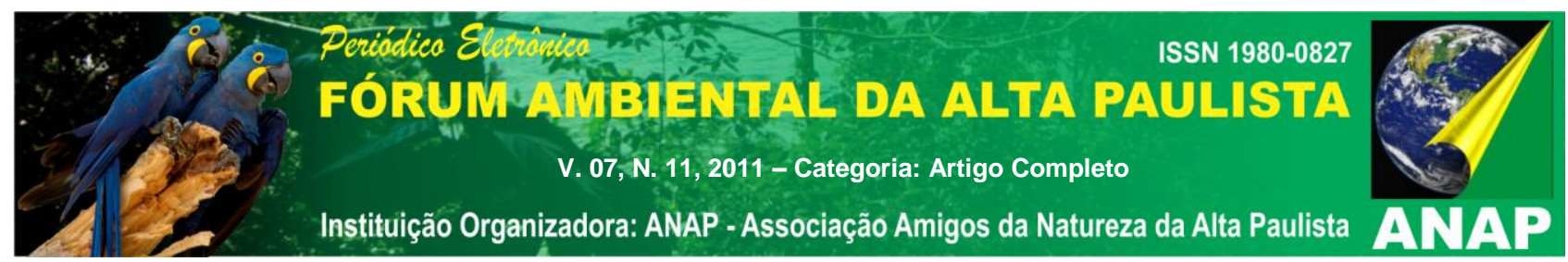

A presente pesquisa apresenta-se como uma importante forma de entender a necessidade da conscientização dos empresários acerca da gestão ambiental como forma de produzir e, ao mesmo tempo, conservar o meio ambiente, buscando melhorar sua imagem perante o mercado consumidor.

De acordo com Novaes (apud DONAIRE 1995, p.34):

As portas do mercado e do lucro se abrem cada vez mais para as empresas que não poluem, poluem menos ou deixam de poluir, e não para as empresas que desprezam as questões ambientais na tentativa de maximizar seus lucros e socializar o prejuízo.

Dessa forma, podemos acrescentar que o público está mais crítico e seletivo, não bastando apenas produzir produtos de qualidade, pois as pessoas estão observando as empresas que não poluem, estando cientes e informadas dos efeitos colaterais que as empresas podem causar ao meio ambiente.

O município de Presidente Prudente-SP desenvolve-se economicamente através dos diversos segmentos produtivos tanto nas atividades ligadas ao setor da agropecuária quanto aos setores industrial, comercial e na prestação de serviços, apresenta-se, ainda, como uma rica fonte de fomento de pesquisas no âmbito do desenvolvimento econômico e social de uma localidade. Com cerca de 204 mil habitantes e um PIB per capita de $R \$$ $12.363,00$, é considerado um dos principais centros urbanos da região conhecida como Alta Sorocabana ${ }^{4}$ e a população prudentina passa a ter interesses acadêmicos e empresariais na busca por informações que contribuam para o entendimento da adequada gestão ambiental adotada pelas organizações.

\subsection{Objetivo Geral}

O presente trabalho de pesquisa buscou demonstrar a necessidade da conscientização acerca da Gestão Ambiental nas empresas como forma de estratégia de marketing apresentando um diferencial dentro do âmbito organizacional para atender a um mercado consumidor preocupado com a qualidade do meio ambiente em que vive ao

\footnotetext{
${ }^{4}$ Fundação SEADE. Cidades paulistas: oportunidades de negócio. Disponível em: < http://www.cidadespaulistas.com.br > acesso em 05/02/2010
} 


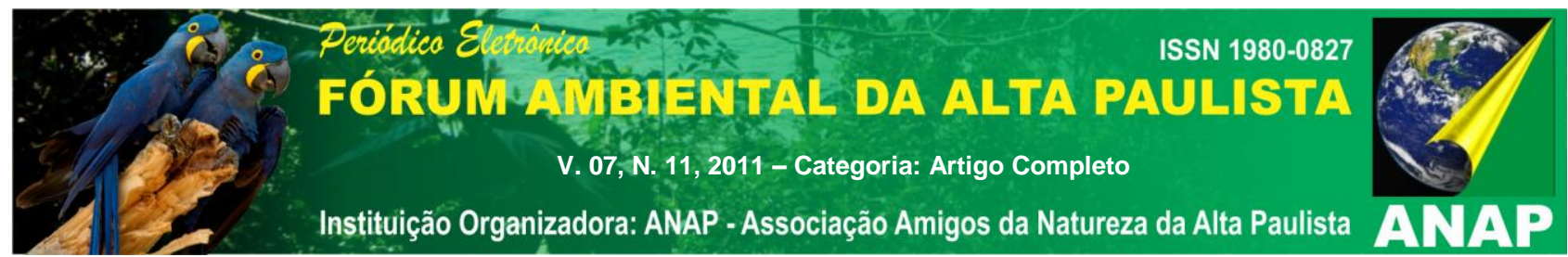

enfocar uma empresa da área de prestação de serviços de saúde atuante no município de Presidente Prudente-SP.

\subsection{Objetivos específicos}

Para o desenvolvimento dos trabalhos de pesquisa, os alunos pesquisadores seguiram os objetivos específicos: a) Identificação dos conceitos de gestão ambiental; b) Verificação do desenvolvimento da preocupação com a gestão ambiental nas empresas; c) Estudos acerca da importância do marketing estratégico como ferramenta de divulgação das chamadas "empresas verde"; d) Coleta e analise dos dados obtidos através de pesquisa a campo.

\subsection{Metodologia de Pesquisa}

O presente o trabalho de pesquisa classifica-se como de abordagem qualiquantitativo e teve como materiais, referencial bibliográfico, estudo documental e gráficos realizados como resultado da elaboração e aplicação do questionário e entrevistas junto a funcionários e consumidores da empresa analisada, fazendo uso de amostragem probabilística aleatória simples para consumidores e estratificada para os funcionários.

O presente projeto de pesquisa fez uso tanto da aplicação de um questionário com perguntas fechadas que forneceram dados quantitativos, ou seja, dados que forneceram dados que possam ser mensurados em valores e quantidades, quanto perguntas abertas que forneceram dados qualitativos, ou seja, dados passíveis de serem analisados e mensurados de acordo com suas características.

\section{ORGANIZAÇÕES E CONSUMIDORES AMBIENTALMENTE CONSCIENTES}

O mundo globalizado em que vivemos, com acentuado aumento no padrão de consumo da população, permite a verificação de que algumas empresas alcançam 


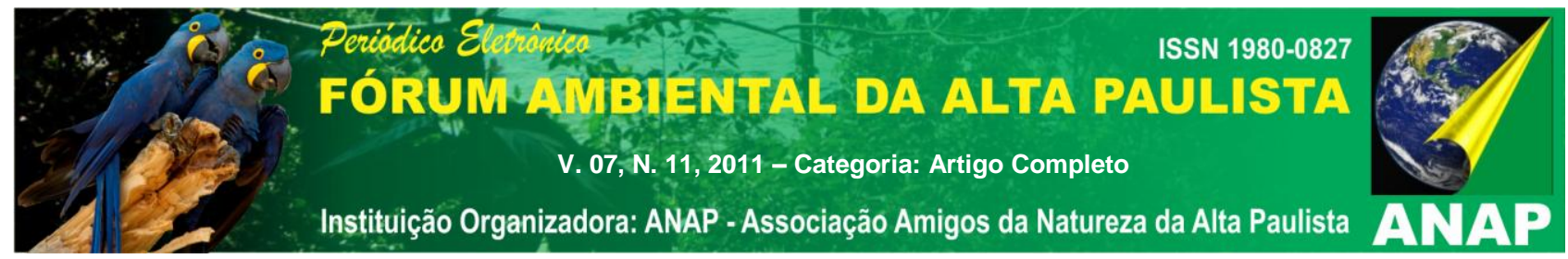

alguma vantagem competitiva ao confeccionar embalagens ou rótulos ousados e diferenciados. Tal vantagem aumenta quando o produto oferecido traz consigo a idéia de que sua utilização está atrelada à imagem de uma empresa que se preocupar com o bemestar ambiental.

Assim, percebemos que atualmente, as organizações estudam e investem em tecnologia limpa, criando produtos, embalagens e rótulos ecologicamente corretos. $\mathrm{O}$ motivo dessa mudança, segundo Oliveira (2008) é de que as organizações deixam de ser encaradas como responsáveis por gerar emprego e renda apenas, e passam a desempenhar um caráter social.

Se as organizações almejarem o sucesso e a satisfação de seus clientes, está nítido que deverão incluir em suas metas organizacional a temática gestão ambiental. A postura deve ser voltada para questões ambientais e segundo Lima \& Oliveira (2003, p.3), "as empresas acabam ganhando melhor imagem institucional e isto pode ser traduzido em mais consumo, mais vendas, melhores empregados, melhores fornecedores, mais acesso ao mercado de capitais."

Dias (2007, p.24) afirma que, "os impactos ambientais estão ligados diretamente ao fluxo de matéria e de energia e, consequentemente, estão intimamente ligados aos produtos".

Empresa e meio ambiente devem interagir-se de maneira equilibrada para que a natureza forneça recursos e a empresa desenvolva produtos corretos ambientalmente, garantindo a preservação da natureza e despertando a satisfação dos clientes.

O público alvo das empresas deve ser este - clientes preocupados com o meio em que vivem e que cobram posturas ecológicas das empresas. A ação positiva e benéfica precisa surgir das duas partes, ou seja, empresa e sociedade. Em suma as organizações, em grande parte já incorporaram a gestão ambiental em suas políticas gerenciais, as que ainda não tomaram alguma postura verde devem rapidamente se mobilizar nesse propósito, pois os consumidores nessa atual conjuntura tornaram-se verdadeiros fiscais ambientais, e esses estão se apresentando fiscais rígidos e corretos, levando as organizações a mostrarem um comportamento ecologicamente consciente.

\subsection{Gestão ambiental e o Marketing verde como diferencial competitivo.}




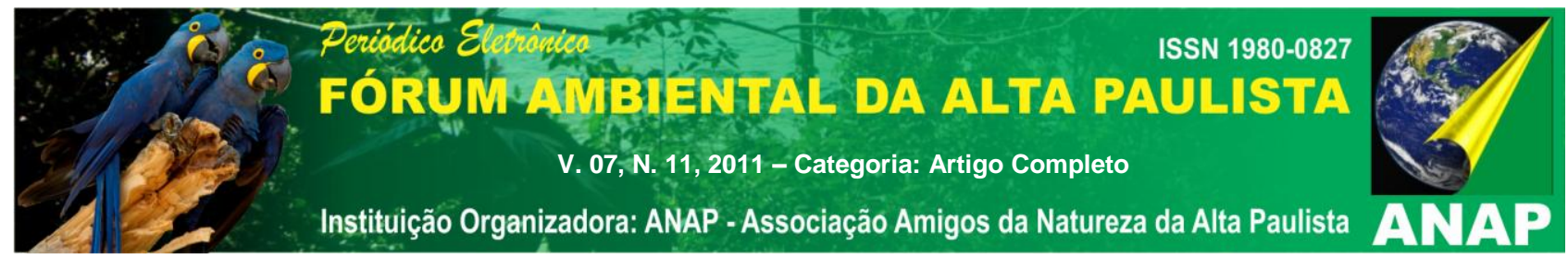

A gestão ambiental surge dentro das empresas ao buscar o relacionamento entre a postura produtiva de uma organização e o respeito ao meio ambiente e as questões ligadas a ele: desperdício, poluição, esgotamento de recursos, entre outros.

Tal aderência acentuada à gestão ambiental é a própria ruptura de pensamento dos consumidores, que ao longo do tempo tornaram-se preocupados com a qualidade de vida e hoje cobram menos desperdícios por parte das organizações.

Com esse novo perfil de sociedade e mais precisamente de consumidores, as companhias devem imediatamente, se atentarem para a adesão a políticas ambientalistas, a fim de cativarem seu publico alvo. Em seu estudo Ottman (1992, p.1) diz que, "os administradores de negócios que puderem atender às demandas de consumidores com produtos ambientalmente saudáveis enquanto as atitudes ainda estão se formando, têm chances de obter mais vantagens".

Tratando-se de empresas prestadoras de serviços, que não lidam com produção efetivamente, esses clientes procuram sinais claros de que a empresa agrega à sua política interna algum aspecto ambiental que permita garantir uma assistência ao meio ambiente. Tal postura ambientalmente correta apresenta-se vital para organizações que pretendam cativar esse novo consumidor e, para tanto, faz-se necessária a sua incorporação à sua cultura organizacional.

Nesse sentido Philippi Junior; Romero e Bruna (2004, p.700) dizem que, "[...] gestão ambiental é o ato de gerir o ambiente, isto é, o ato de administrar, dirigir ou reger as partes constitutivas do meio ambiente". Com base nesse conceito as empresas precisam se adaptar para o regimento e a administração ambiental, quebrando o paradigma de que necessitam apenas encontrar soluções para problemas gerenciais e técnicos.

Sabe-se que o processo administrativo passa pelas empresas de forma programada, seguindo etapas importantes - planejamento, organização, direção e controle. Todas as decisões gerenciais tomadas pelos gestores caminham nessa proposta, visando maior aproveitamento dos recursos e maior lucratividade. A questão ambiental tão bem definida deve permear e tangenciar esse esquema de processo administrativo, para que também se tenha uma otimização concernente ao próprio 


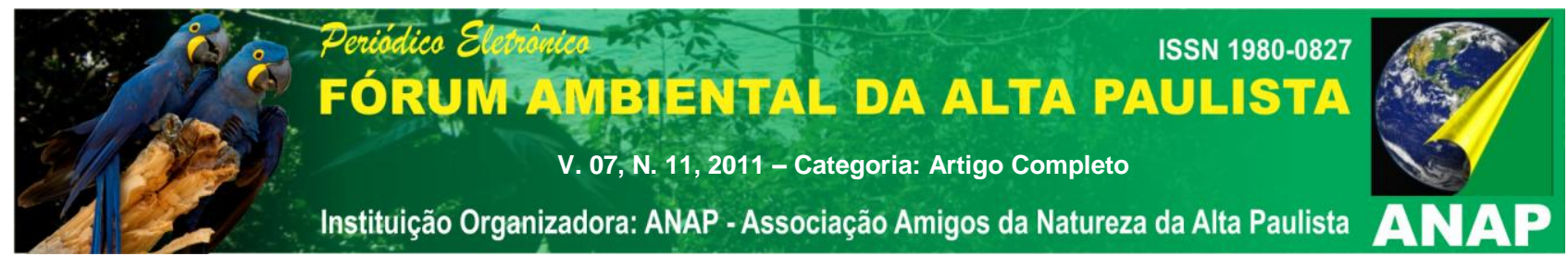

itinerário fabril e até mesmo se obtenha menos impactos ambientais que acabam por aumentar a crise ecológica.

Considerando esses aspectos conceituais Philippi Junior, Romero e Bruna (2004, p.700) concluem dizendo:

Destaca-se que gestão ambiental é o ato de administrar, de dirigir ou reger os ecossistemas naturais e sociais em que se insere o homem, individual e socialmente, num processo de interação entre as atividades que exerce, buscando a preservação dos recursos naturais e das características essenciais do entorno, de acordo com padrões de qualidade. $O$ objetivo último é estabelecer, recuperar ou manter o equilíbrio entre natureza e homem.

Essa aderência à gestão ambiental por parte das organizações garante, além de assistência ao meio ambiente, a satisfação do consumidor e promove um novo ramo do marketing - o marketing verde. A relação sustentável das empresas com a natureza deve ser mostrada para seus consumidores e para a sociedade, e a forma que encontraram para publicar essa postura ecologicamente correta foi através do marketing sustentável ou marketing verde. Pensando nesse sentido, Dias (2007, p.19) diz:

A sustentabilidade do marketing significa que toda a sua organização está voltada para a diminuição dos impactos negativos sobre os ecossistemas, e ao mesmo tempo que continua atendendo às necessidades dos consumidores, fornecendo-lhes os produtos que os beneficiam e à sociedade com um todo.

Daí em diante o marketing ganhou uma conotação social relacionada à qualidade de vida. O que difere marketing e marketing verde é o objetivo central, ou seja, enquanto o primeiro visa apenas divulgar produtos de forma chamativa e atrativa, o segundo visa passar uma imagem de que aquela organização ou produto está em sintonia com o meio ambiente e investe na preservação da natureza.

O marketing verde também leva consigo o aspecto de propagação e divulgação de um produto para a sociedade, entretanto, ganha uma roupagem social, onde além de vender algo vende uma imagem sadia e consciente da empresa, demonstrando uma relação consumo - meio ambiente. Tudo isso se dá pela razão de que a população consumista tornou-se mais sensível concernente aos temas ambientais. 


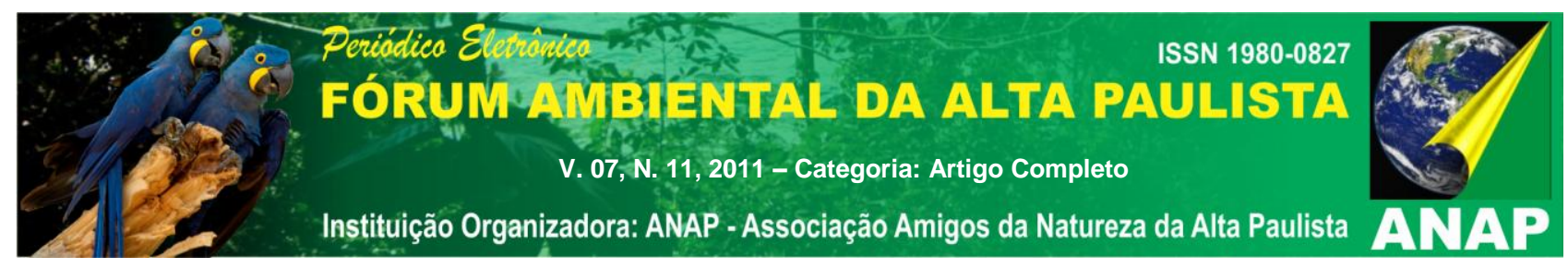

\section{RESULTADOS DA PESQUISA DE CAMPO}

A presente pesquisa obteve informações empíricas por meio de uma abordagem quali-quantitativo, fornecendo, após a pesquisa de campo, através de questionário aplicado a funcionários e usuários da empresa analisada, informações que solidificam o estudo bibliográfico demonstrado, bem como possibilita uma análise local e uma visão do perfil da empresa em estudo.

\subsection{Considerações acerca dos dados obtidos junto a funcionários da empresa analisada.}

Analisando os dados colhidos a partir da aplicação do questionário, nota-se que a renda familiar dos funcionários gira em torno de 01 a 03 salários mínimos e percebe-se que os funcionários entrevistados consideram que as pessoas optam pelos serviços da empresa não por uma questão ambiental ligada a empresa. Isso é confirmado quando a maioria responde dizendo que a escolha está ligada aos valores mais acessíveis oferecidos e uma parcela responde dizendo que a escolha se dá pela credibilidade da empresa e uma parcela menor considera que a opção é devida a indicação de amigos. Para todos os funcionários entrevistados a empresa analisada não desenvolve nenhum programa relacionado à questão ambiental. A maioria dos entrevistados responde ainda que a empresa analisada não oferece qualificação e treinamento para programas ambientais.

\subsection{Considerações acerca dos dados obtidos junto a usuários da empresa analisada.}

Após a aplicação do questionário aos usuários da empresa prestadora de serviços de saúde analisada é possível considerar alguns aspectos. A renda familiar esta entre 01 e 03 salários mínimos, o que preliminarmente pode confirmar o que foi obtido como 


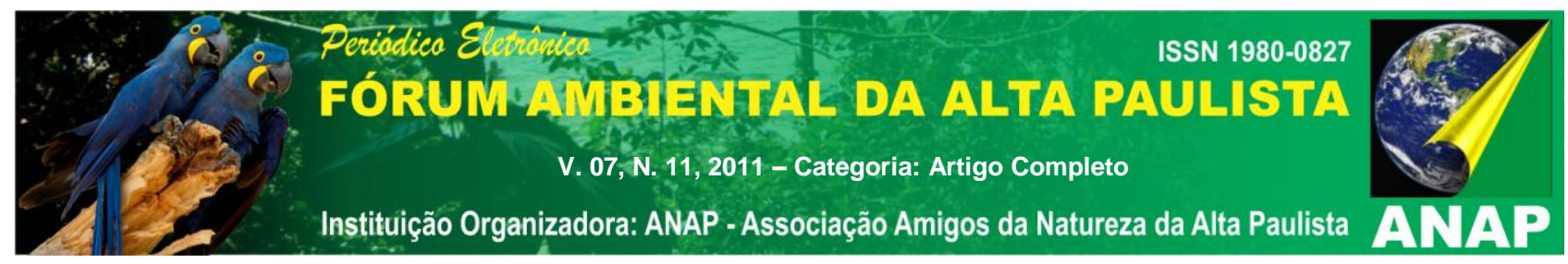

resposta dos funcionários ao dizerem que a opção das pessoas pela empresa e seus serviços é pelos valores mais acessíveis.

A maior parte dos entrevistados é usuário os serviços fornecidos pela empresa analisada a menos de 01 ano. Dos planos comercializados, o que apresenta maior adesão por parte dos usuários é o plano bronze sendo o mais barato, o que também possibilita a princípio dizer que a opção pela empresa analisada está ligada aos valores mais acessíveis.

Os usuários utilizam os serviços oferecidos em torno de uma vez por mês e mais de uma vez por mês, sendo que todos responderam que utilizam com mais freqüência consultas em consultório. Ao se perguntar qual o motivo que levou a pessoa a optar pela empresa a maior parte diz de fato que foi por razão dos valores mais acessíveis, confirmando o que já havia sido dito pelos funcionários e o que foi preliminarmente concluído nessa análise.

Para todos os usuários, a empresa analisada não oferece nenhum programa especifico envolvendo a questão ambiental e todos respondem dizendo também que a empresa deveria sim desenvolver algum programa ambiental. Como proposta de programa ambiental os usuários entrevistados, na sua maioria, dizem que deve ser a não utilização de sacolas plásticas em Presidente Prudente e uma parcela diz que deve ser a reciclagem.

\section{CONCLUSÃO}

A presente pesquisa visou analisar a gestão ambiental em seus diversos aspectos teóricos para posteriormente aplicá-los na empresa analisada, empresa prudentina prestadora de serviços de plano de saúde vinculada a ANS (Agência Nacional de Saúde Suplementar). Viu-se necessário nos tempos atuais a importância de se adquirir uma postura ecologicamente correta nas empresas, pois além de colaborar com a natureza os consumidores atuais cobram tal postura das organizações.

No início da pesquisa, a empresa analisada não possuía nenhuma política ou plano de ação voltadas a questão ambiental. Ao se aplicar questionários direcionados aos 


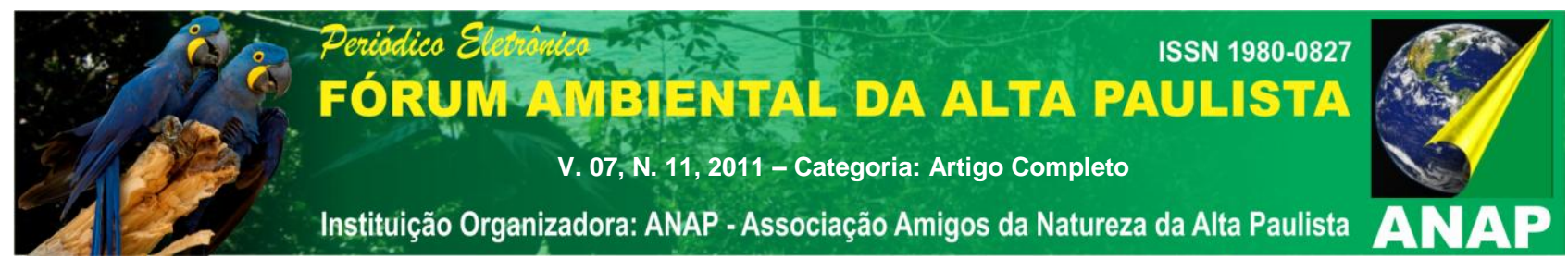

funcionários e usuários, verificou-se que a totalidade deseja que a empresa aderisse a gestão ambiental adotando algum programa incentivador e assistencial ao meio natural.

Descartou-se por parte da direção da empresa a possibilidade de se conquistar certificados, sendo a principio fora de cogitação. Entretanto no decorrer desse trabalho, a direção da citada empresa concluiu que de fato era importante a adesão a propostas ambientais e satisfazer esse desejo dos usuários e funcionários. Como primeiro gesto concreto focando a conservação do meio ambiente, foram confeccionadas eco-bags (sacolas industrializados $100 \%$ algodão) que substituem as sacolas plásticas e distribuídas como brindes a alguns grupos de usuários de seus serviços.

Assim, foi realizada uma campanha divulgada por meio de várias mídias publicitárias. Com isso a empresa utilizou-se do marketing verde para publicar essa iniciativa e conquistar diferencial estratégico frente os concorrentes. Essa iniciativa, a principio, esteve em vigência no mês de maio de 2011 em comemoração ao mês das mães. Devido ao sucesso da campanha, a direção da empresa decidiu prolongar essa campanha por prazo indeterminado.

Foram confeccionadas novas eco-bags a fim de alcançar um número expressivo de usuários. A cada plano individual vendido o cliente leva a eco-bag. Portanto a proposta dos usuários e funcionários em reduzir o uso de sacolas plásticas na cidade foi atendida pela empresa, que visualiza ser realmente uma maneira de contribuir com o meio ambiente.

Assim, podemos afirmar que a presente pesquisa contribuiu para o início de uma conscientização ambiental por parte da empresa pesquisada enfatizando a importância da aplicação do marketing verde nas organizações.

\section{REFERÊNCIAS}

DIAS, R. Marketing ambiental: ética, responsabilidade social e competitividade nos negócios. São Paulo: Atlas, 2007

DONAIRE, D. Gestão ambiental na empresa. São Paulo: Atlas, 1995. 


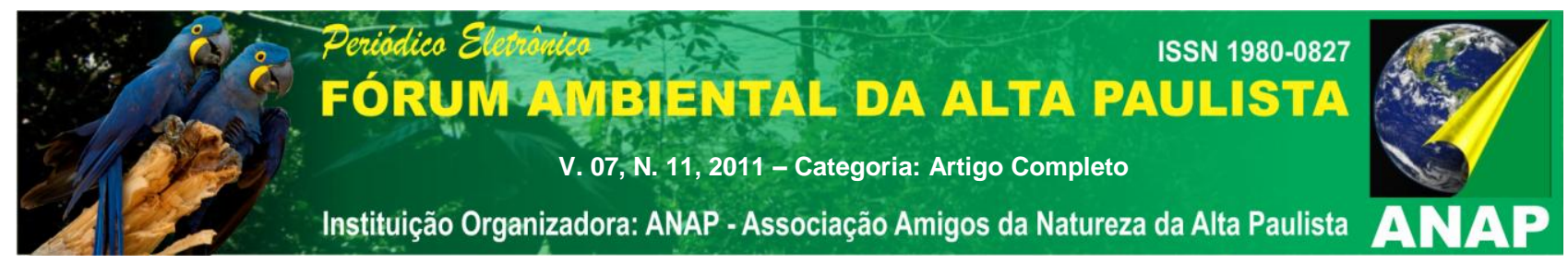

LIMA, B.F. ; OLIVEIRA, F.A. Gestão ambiental nas empresas. 2003. 51 fls. Monografia graduação - Faculdade de Ciências Jurídicas, Administrativas e Contábeis - Curso de Administração, Universidade do Oeste Paulista-UNOESTE, Presidente Prudente, 2003.

MAXIMIANO, A. C. A. Introdução à Administração. São Paulo: Atlas, 1995

OLIVEIRA, J. A. P. de. Empresas na sociedade : sustentabilidade e responsabilidade social. Rio de Janeiro: Elsevier, 2008.

OTTMAN, J. A. Marketing verde. Rio de Janeiro: Makron Books, 1994

PHILIPPI JÚNIOR, A. ;ROMÉRO, M. ; BRUNA, G. C. Curso de gestão ambiental.1.ed. Barueri: Manole, 2004. 